\title{
Entre a voz e o silêncio: literatura e espiritualidade nos mosteiros femininos
}

\author{
Isabel Morujão* \\ isabelmorujao@mail.telepac.pt
}

\author{
"Dando lugar a la pasión y ternura de mujer [...] \\ o siguiendo la luz del corazón". \\ María de San José - Carta de una pobre e presa descalza
}

Resumo: Levando-se em conta o lugar e o papel da religiosa no mundo claustral português (na sua articulação com o estatuto cultural da mulher portuguesa, entre os séculos XVI e XVIII), procurar-se-á entender, através de fontes diversas, a emergência da literatura monástica feminina em Portugal, resultante de uma tensão estruturante entre a voz e o silêncio. A percepção (no interior e no exterior dos mosteiros) da sua função, da sua origem, das suas vias de afirmação e difusão permitirá esclarecer esta visibilidade feminina no domínio da literatura e da espiritualidade. De qualquer forma, sempre será conveniente recordar que a complexidade, extensão e diversidade desta literatura tornarão sempre insuficientes as constataçōes feitas.

Palavras-chave: Escrita monástica feminina; escrita autobiogáfica; diálogos místicos; identidade feminina

Abstract: Taking into consideration the place and role of the religious woman in the Portuguese cloistered world (in their relationship with the cultural status of the Portuguese woman, between the sixteenth and eighteenth centuries), this paper will seek to understand through various sources, the emergence of female monastic literature in Portugal, resulting from a structural tension between voice and silence. The perception (inside and outside the feminine monasteries) of its function, its origin, its means of affirmation and diffusion will allow to clarify the visibility of women in the field of literature and spirituality. Anyway, it must be recalled that the complexity, scope and diversity of female monastic literature will always make insufficient the findings presented here.

Keywords:.Female monastic literature; autobiograhic texts; mystic dialogues; female identity

\footnotetext{
* Faculdade de Letras da Universidade do Porto; CITCEM (Centro de Investigação Transdisciplinar Cultura, Espaço e Memória).
} 


\section{I - Mulher e normas: Preâmbulo}

A vida da mulher portuguesa em clausura é uma realidade que, tendo começado pelo séc. XII e mantendo-se como forma reconhecida e superior de vida cristã ao longo da Idade Média, conheceu recrudescida expressão e significado na Idade Moderna.

Os dados fornecidos por SOUSA ${ }^{1}$ apresentam um claro crescimento, entre os sécs. XIV e XVI, de conventos femininos em Portugal (particularmente entre as ordens dos frades menores e dos pregadores), que, nos alvores do séc. XVII constituíam, de fato, uma forma de vida bem delineada e expressiva da espiritualidade nascida de Trento.

O séc. XVII abriu as portas à valorização da vida feminina intraclaustral e tornou natural a curiosidade pela vida destas mulheres que viviam retiradas do mundo. A proximidade com Deus e o estatuto de Esposas de Cristo reacendido com as declaraçôes de Trento ${ }^{2}$ terão com certeza estado na origem do reconhecimento e da valorização destas mulheres, mais do que das outras, que, cumprindo os deveres protocolares que a sociedade lhes delimitava, falavam pouco, saíam menos e muito raramente davam nas vistas ${ }^{3}$. Apesar de tudo, à dama de corte, tal como pioneira e ousadamente a esboçara CASTIGLIONE no livro III de $O$ Cortes $\tilde{a} o^{4}$, já se exigia que soubesse ler, falar em variados registros e opinar em matéria literária, etc. Mas não esqueçamos que Portugal, embora tenha provavelmente conhecido essa

\footnotetext{
${ }^{1}$ Cf. B.V. SOUSA, Ordens religiosas em Portugal.

${ }^{2} \mathrm{Na}$ sua sessão XXV, o Concílio de Trento decretou, no cap. XX, que, para o restabelecimento da doutrina eclesiástica junto do povo cristão, os imperadores, reis, príncipes, Estados e outros assumissem o dever de respeitar e proteger a Igreja. Cf. G.ALBERIGO (org.). LES Conciles Ecuméniques 2.

${ }^{3}$ A sermonária, idealmente adequando o sermão às circunstâncias do auditório, no âmbito do aptus dicere, constitui um excelente observatório sobre ideologias, práticas e representaçôes culturais. Nesse sentido, alguns sermōes do Padre Antônio Vieira são bem paradigmáticos dos valores que se pretendiam incutir nas senhoras portuguesas em particular, e também nas religiosas: "Oh quem me dera ter neste auditório todas as senhoras do mundo tão prendadas, e tão presas, tão tidas e tão retidas das vaidades do mesmo mundo; para que vissem o de que só se haviam de deixar prender e deter, à imitação da maior Senhora e Rainha de todas! Tudo quanto a apreensão e fantasia feminil estima e preza viu a benditíssima Virgem no grande teatro de Israel, de que Deus a fizera herdeira" (P.A. VIEIRA, Sermões, p.146). No "Sermão da Exaltação da Santa Cruz, pregado no Convento da Anunciada em Lisboa, em 1645", assinala explicitamente os deveres do silêncio entre as religiosas de clausura e, ainda, as circunstâncias em que podiam falar, nos locutórios: "Só vejo que me replicam que o silêncio será grande martírio, mas que as Religiosas (com quem e de quem particularmente falo) também falam. Pudera tapar as bocas a todos com responder que ainda que falam as Religiosas, essas mesmas palavras saem tão crucificadas quantas são as cruzes de uma grade, mas não é isto o que respondo. Digo que o falar das Religiosas não diminui o martírio da Cruz, porque ainda que falam alguma vez, falam com tais circunstâncias, que fazem maior o tormento, porque o seu falar é com escutas, e falar com escuta é maior pena que calar" [...)] A outra razão é porque ainda que as Religiosas falam, falam com licença; e para os que sabemos que cousa é Religião, é certo que mais custa a licença que o silêncio. E a razão é clara: porque o silêncio é calar e a licença é pedir, e muito mais custa abrir a boca para pedir, que fechá-la para calar" (P.A. VIEIRA, Sermōes, pp. 63-64).
}

${ }^{4}$ Cf. B.CASTIGLIONE, Il Cortegiano. 
gramática de vida de corte que constitui $O$ Cortesãa $0^{5}$, não abriu tão cedo as suas portas a estas renovaçôes vindas do estrangeiro, pelo que só muito tardiamente a mulher de corte se foi libertando do seu lugar na almofada e no estrado ${ }^{6}$.

Assim, a identidade da mulher portuguesa construía-se no silêncio, forjada num quadro de valores enraizadamente católico, à semelhança da imagem da Virgem que, no Evangelho, só fala por sete vezes. Sobre a mulher em geral recomendava Diogo Paiva de ANDRADA, no Casamento Perfeito:

Esta moderação de toucados, e trajos há-de ser sempre misturada com outra não menos importante e substancial, que é a da língua; porque escusado seria mostrar-se uma mulher honesta em sua pessoa, se se mostrasse desenvolta em suas palavras. [...] Pintavam os antigos a Deusa Vénus com os pés em cima de um cágado, e a razão era, porque como este animal, por não ter voz nenhuma, nem sair nunca, ou poucas vezes do lugar, em que está posto, era símbolo do silêncio, e recolhimento, queria que as mulheres significadas pela imagem de Vénus, se lembrassem, que tinham obrigação de andar pouco, e falar menos. E foi sempre tão estranhada, e mal recebida, particularmente nas casadas, qualquer pequena soltura de língua.?

Esse silêncio acompanhava a mulher na vida de clausura, onde era valorizado como meio particularmente eficaz para a oração, a intimidade com Deus e a caminhada na vida espiritual. Os manuais sobre perfeição religiosa, as regras monásticas, os tratados de moral, a sermonária e alguns escritores de um modo geral sublinhavam essa virtude no feminino, constituída pela escassez de palavras. As regras monásticas determinavam rigorosamente os momentos de recreação, nos quais as religiosas poderiam falar umas com as outras, como forma de quebrar esse silêncio que, sem essas rupturas que pontuavam o quotidiano da vida conventual, não saberia ser vivido com o devido apreço, respeito e benefício.

$\mathrm{Na}$ passagem do século XVI para o século XVII, os esforços tridentinos no sentido de restaurar a clausura feminina estreitaram o leque de leituras permitidas nos conventos, procurando erradicar livros profanos ${ }^{8}$ e diminuir ou pelo

\footnotetext{
${ }^{5}$ Em Menina e Moça de Bernardim Ribeiro (1ª edição em Ferrara, 1554), os conselhos de Lamentor a Arima, antes desta partir para o paço, de alguma forma replicam o modelo de comportamento da dama de palácio construído no Livro III d' O Cortesão, constituindo, por isso, indícios da recepção da obra em contexto português e sugerindo Bernardim Ribeiro como leitor de Castiglione.

${ }^{6}$ Ss representaçôes, para essa época, de senhoras portuguesas a ler são, praticamente, inexistentes. Em Itália, por exemplo, onde várias modalidades de escrita feminina emergem desde muito cedo, são comuns as representações de mulheres a ler e a escrever. Sobre as representaçōes da mulher e do livro, cf. J.H.M. TAYLOR; L.SMITH, Women and the book.

7 D.P. de ANDRADA, Casamento Perfeito.

${ }^{8}$ Será sempre de assinalar, nesse processo de controle da leitura e da escrita entre a clausura feminina, o impacto dos índices de obras proibidas, que, depois do primeiro e grande Índice de Valdès, em 1559, deram forma a uma intrincada associação entre leitura, culpa e perigo, cujo alcance, em toda a Península Ibérica, é ainda hoje difícil de avaliar.
} 
menos vigiar atentamente a prática do carteio e a posse de instrumentos para a prática da escrita. "Nas cartas que se mandam e se recebem atenda V. M. o que pede a observância e clama a razão. Pois se a Prelada deve ser toda olhos, cartas e grades pedem a principal vigilância desses olhos", recomenda o P.e Manuel VELHO9. Em 1734, Soror Maria do CÉU fará passar às suas religiosas, em Aves Ilustradas em Avisos, logo reeditada quatro anos mais tarde, a mesma atitude de silêncio e de necessidade de preservar a visibilidade das religiosas do exterior do convento ${ }^{10}$.

Não obstante, o também tridentino imperativo de que todas as instâncias religiosas participassem na consolidação da doutrina cristã, contribuindo para a sua difusão e impacto junto dos fiéis, muitas vezes se sobrepôs às restrições de leituras por parte de religiosas, ainda que, em alguns conventos, pelo menos as noviças fossem particularmente acompanhadas nesse seu gradual contato com os livros. Soror Violante de Jesus foi, nesse sentido, conforme relata Fr. Jerônimo de Belém, atentamente vigiada, punida até com o adiamento da permissão de ler Nieremberg. Nos sermões do Padre Antônio VIEIRA perpassam inúmeras referências a mulheres devotas e a monjas, a todas aconselhando o pregador a usar de poucas leituras:

E se querem parecer doutas, ou doutoras, o mesmo documento têm na Ave-Maria. Sendo menino, S. Tomás tinha nas mãos um papel em que estava escrita a Ave Maria. E como lho quisessem tirar das mãos, o menino, com instinto do céu, o meteu na boca, e o mastigou, e o engoliu. Mastiguem bem no Rosário a Ave-Maria, e serão tão doutoras como $\mathrm{S}$. Tomás.

E ainda:

No Breviário é verdade que rezais ou pronunciais dez mil palavras; mas também é verdade que as não entendeis: logo melhor é no Rosário não só rezar cinco décadas, ou cinco oraçōes inteiras, mas cinco palavras somente do Padre-Nosso, e Ave-Maria; porque é na vossa língua que entendeis o que dizeis a Deus. ${ }^{11}$

A exceção era só feita às religiosas, obrigadas a lerem em latim pela hierarquia eclesiástica, ainda que pudessem não o entender ${ }^{12}$.

\footnotetext{
${ }^{9}$ M. VELHO, Cartas Directivas e Doutrinais, p.383.

10 "Fazei, Senhora, guardar o silêncio, porque aí assiste Deus, aonde o há" (S.M. de CÉU, Aves Ilustradas em Avisos para as Religiosas servirem os oficios nos seus Mosteiros, p.17) "Sejam as vossas Freiras tesouro escondido em campo manifesto, quereis que as venerem como deusas, fazei com que as conheçam só por fé, são de Deus, não as vejam os homens" (p.6). "Senhora, criais as vossas Noviças para Religiosas, criai-as com obediência: uma Freira sem obediência é cavalo sem freio, barco sem remos, nau sem piloto, edifício sem alicerce, horto sem muros" (p.43). ${ }^{11}$ VIEIRA, in J.E. FRANCO; M.I. MORÁN CABANAS, O Padre Antônio Vieira e as Mulheres .

${ }^{12}$ CÉU situa-nos bem relativamente à prática da leitura em latim no interior dos mosteiros: "falar com o livro em Latim e com as que me ficam ao lado em Português, com os pensamentos em todas as línguas, isso será fazer de uma hora de Deus uma torre de Babilónia”. (S.M. de CÉU, Aves Ilustradas em Avisos, p. 30)
} 
Tempos conturbados aqueles, em que os pregadores faziam recomendaçōes contraditórias às senhoras, cujo estatuto intelectual se encontrava ainda oscilante entre a boa-vontade masculina, a gradual afirmação feminina e o desprezo de quem via nas mulheres seres naturalmente criados como inferiores no plano de Deus. De fato, na mesma época, Fr. Antônio das CHAGAS recomendava por carta às suas orientadas que lessem: "O tempo que puder ter para se divertir, leia, $e$ leia vidas de santos, ou o Combate Espiritual, ou o Amor de Deus de S. Francisco de Sales, ou o Padre Puente". ${ }^{13}$

De qualquer forma, era distinto o caminho que conduzia à letra lida e à letra escrita, ainda que este último pressupusesse o primeiro.

\section{II - Do silêncio ao cicio}

Ao enunciar a sua proposta para uma ontotopologia, o filósofo Martin HEIDEGGER $^{14}$ afirma que existir é habitar um espaço e que a habitação é o traço essencial da condição humana. Nesse sentido, pensar a existência deveria constituir um ato indissociável da relação com um espaço determinado, sendo por isso necessário encontrar o "isto" a partir do qual alguma coisa toma lugar e começa a existir. Transferindo essas reflexões do seu contexto inicial ${ }^{15}$ para o domínio da existência feminina em clausura, será interessante levar em conta a associação entre a existência e o espaço em que ocorre, para se ver como este último se torna de fato determinante para a emergência e visibilidade da escrita feminina. Em casa, no ambiente familiar, as senhoras poderiam ler (sobretudo se o pai ou o marido o permitissem, como propõe Vives, no séc. XVI, na Instrucción de la mujer cristiana) e também escrever; no convento, ainda que condicionadas por orientadores espirituais e mestras de noviças, poderiam ler mais metodicamente, dependendo também a expansão desta atividade de escrita e de leitura, da especificidade de cada casa religiosa. Em casa, o que escreviam raramente chegou aos prelos, mas o que escreviam na clausura, esse lugar visto pela cidade como local de piedade e santidade $^{16}$, era objeto da curiosidade exterior e requisitado para honras de prelo ${ }^{17}$.

\footnotetext{
${ }^{13}$ Fr. A. De CHAGAS, Cartas Espirituais, p.144-45.

${ }^{14}$ Cf. M. HEIDEGGER, L'Être et le Temps; M. HEIDEGGER, L'art et l'espace. In : Questions IV.

${ }^{15}$ Heidegger procurou, com as suas propostas, responder à questão da habitação na Terra, que ele encarava como o problema mais incontestado do seu tempo.

${ }^{16} \mathrm{O}$ próprio espaço geográfico em que assentava a construção de alguns mosteiros resultou, muitas vezes, de sonhos, avisos e indicações de proveniência tida como santa ou divina pelos seus fundadores.

${ }^{17}$ É curioso perceber como o discurso que propõe a inferioridade da mulher radica numa defesa contra eventuais riscos de sedução. Entretanto, alguns casos, embora isolados, revelam como, entre certos sectores, as mulheres eram vistas como mais predispostas à devoção do que os homens. Guillaume de Montreuil ilustra bem esta orientação. Entretanto, o topos da inferioridade retoma vigor sob a influência da Ética e da Política de Aristóteles, perspectivando-se a mulher como ser acima de tudo passional e irracional, afetivo e excessivo, devendo por isso obediência e subordinação ao homem (cf. N.BÉRIOU, L'Avènement des maîtres de la Parole, pp.300-303).
} 
Assim, no âmbito dos rituais que envolviam a vida religiosa - que se supunha fosse um caminho em direção a uma maior santidade e a um crescimento da religiosa na intimidade com Deus - a confissão, as orientações da Mestra de Noviças e da Prelada, as orientações espirituais dos confessores etc. permitiam o desvelar de uma vida interior que, não fossem esses momentos, seria só do conhecimento da própria religiosa. A consciência de ser mulher e, logo, inferior, juntamente com a consciência que a vida religiosa fazia crescer cada dia nas monjas de serem as mais indignas servas de Cristo, levava as religiosas a terem dúvidas quanto ao mérito de lhes poder suceder qualquer experiência mais íntima, profunda ou intensa de presença de Deus. Por isso expunham as dúvidas e escrúpulos que sentiam ao seu confessor, no sentido de apurarem ambos, em conjunto, se era presença divina ou tentação demoníaca a privacidade que muitas sentiam com o divino Esposo. E assim, o silêncio em que poderiam ter guardado as suas emoções religiosas dá lugar ao cicio contínuo e sistemático das conversas no confessionário, de onde muitas vezes viria o incitamento, sob preceito de obediência, a que as religiosas passassem as suas experiências para o papel, escrevendo a sua autobiografia; ou a que dessem, por $\operatorname{carta}^{18}$, conta detalhada das suas vivências interiores e espirituais mais extraordinárias, como visões, conversas com Cristo ou os santos, êxtases, etc.

Surge desse modo, sob o signo do mandado do confessor e do preceito de obediência, uma vasta zona de escrita espiritual feminina, mais literária nuns casos, menos noutros (mas em todo o caso emergindo de um contexto não literário), de que infelizmente temos poucos testemunhos hoje. A matéria destas inquietações espirituais devia ser considerada tão delicada e perigosa naquela época de controlo, suspeitas e vigílias face a eventuais misticismos menos ortodoxos (sobretudo depois dos primeiros condenados por molinosismo, em 1687), que provavelmente foram parar ao fogo as inúmeras cartas que as religiosas portuguesas escreveram aos seus diretores espirituais, mesmo por iniciativa própria e sem os constrangimentos da obediência. De fato, nas Cartas Espirituais de Fr. Antônio das CHAGAS, editadas depois da sua morte entre 1684 e 1687, grande parte da correspondência deste religioso franciscano é dirigida a religiosas, em resposta a dúvidas que tinham e que lhe expunham por carta, procurando apaziguamento. Mas as cartas das religiosas não apareceram quando da edição. Ou as terá queimado o próprio Chagas, por andar em viagem e ter receio de extravios delicados, ou as terá remetido juntamente com a resposta para os conventos e aí terão sido destruídas pelas religiosas, como matéria do foro privado.

Mas nem sempre a escrita surge na clausura feminina por incitamento masculino. Muitas religiosas escreveram por impulso próprio e, ainda, no âmbito de

\footnotetext{
${ }^{18}$ Cf. AA.VV, Per lettera, particularmente a parte III, "Lettere di religiose”.
} 
uma prática de sociabilidade que ligou muitas vezes os mosteiros à cidade. Após a morte de algumas religiosas mais admiradas pela sua santidade, tentou-se várias vezes editar os seus escritos (quando os tinham), ora sob a forma de biografia ou relato de vida, ora sob a apresentação de cartas anotadas. Estão neste caso, por exemplo, as Cartas que escrevia a seu confessor para noticias da sua consciência e por preceito do mesmo a serva de Deus Soror Maria Joana, religiosa de S. Francisco no Louriçal ou a Vida interior da Madre Maria Micaela de S. Bernardo, religiosa do Real Mosteiro de S. Dionisio de Odivelas, dando conta ao seu confessor.

Saliente-se, todavia, que o desaparecimento dos manuscritos autógrafos (o autor da compilação e anotações das cartas de Sor Joana afirma que o original se encontrava no arquivo do convento do Louriçal), neste caso como em outros, traçará sempre um destino provisório e ilusório à restituição da relação da mulher religiosa com a sua própria escrita. Deparamo-nos, pois, invariavelmente, com um texto riscado por mão anônima, em que a ausência de assinatura parece legar à posteridade o testemunho de uma escrita sem corpo, quando, pelo menos algumas vezes, fora produzida com o próprio corpo. Basta lembrar a Carta de Escravidão da Madre carmelita Mariana Josefa Joaquina de Jesus ${ }^{19}$, religiosa do Convento de Santa Teresa de Carnide, pela qual esta que se compromete a ser eternamente escrava de Jesus, Maria e José, redigida e assinada usando como tinta o seu próprio sangue, jorrado da aplicação rigorosa de disciplinas ${ }^{20}$ : "sirva de testemunha este sangue, esta Escritura" 21 .

Após o Concílio de Trento assistiu-se, como se sabe, a uma vasta produção biográfica, que procurava glorificar as ordens religiosas e, simultaneamente, propor imagens modelares e ideais do mundo conventual. ${ }^{22}$ Também as autobiografias redigidas por religiosas por ordem do seu confessor se tornaram prática corrente ao longo dos séculos XVII e XVIII, ainda que algumas religiosas pudessem estar já muito perto da morte (como sucedeu com Soror Damiana de Jesus, dominicana de Lisboa, que por terem ardido os seus registos autobiográficos por ocasião do terramoto, se lhe solicitou que reescrevesse a sua vida, mesmo estando a religiosa em adiantada fase de idade e doença, razão pela qual tão pouco deixou escrito).

Contrariamente às biografias, quase nenhuma autobiografia foi editada, tendo João Palma-Ferreira, em 1983, procedido à edição da Relação (fiel e verdadeira)

\footnotetext{
${ }^{19}$ Cf. ANÔNIMO, Breve Recopilação da vida e morte de Soror Catarina do Salvador.

${ }^{20}$ Esse expediente deveria ser bastante comum na escrita das religiosas, uma forma, talvez, também, de se punirem pela ousadia da escrita. Soror Tomásia Caetana de Santa Maria (cf. S.T.C. de SANTA MARIA, Expressões de um devoto arrependimento à imagem de Cristo Crucificado), numa das poucas poesias devotas que produziu, aludiu justamente a esta temática da escrita com sangue: Agora para escrever / farei do meu sangue tinta/ porque dentro no meu peito / tenha pena, e escrivaninha."

${ }^{21}$ Cf. ANÔNIMO, Breve Recopilação da vida e morte de Soror Catarina do Salvador.

${ }^{22}$ Cf. I.POUTRIN, Le Voile et la plume, pp.20-21.
} 
que dá dos sucessos da sua vida a criatura mais ingrata ao seu Criador, redigida entre 1681 e 1703, por Soror Clara do Santíssimo Sacramento, religiosa do Convento da Madre de Deus de Xabregas, por ordem sucessivamente repetida do seu confessor, Frei Filipe de Santiago. As restantes jazem em arquivos e bibliotecas, embora seja grande a sua utilidade para a percepção da prática de escrita no interior dos mosteiros femininos, da sua abrangência, da sua função. Desconsideradas provavelmente por serem textos escritos por mulheres, a propósito da literatura feminina produzida em Espanha na Idade Moderna, chamou já a atenção para o fato curioso de não existir correspondência, em termos de fortuna do gênero, no universo masculino da época ${ }^{23}$, embora, para Portugal, se saiba que o Padre Antônio Vieira, por exemplo, tinha um diário, hoje desaparecido, de que se terá servido André de Barros e que o padre jesuíta João Antônio Andreoni, por quem Vieira tinha grande respeito e admiração, descreveu ${ }^{24}$ ou poupadas à impressão por constituírem matéria íntima e algo polêmica, o seu levantamento tem vindo recentemente a ser realizado exaustivamente por mim, para efeitos de investigação.

Nesse âmbito da edição ou intenção de edição de escritos espirituais de religiosas nos séculos XVII e XVIII, há algumas considerações curiosas que importa aqui fazer. Por um lado, são textos que se decidiu divulgar umas vezes só para uso de religiosas, outras para proveito das almas em geral. Foi o que pretendeu o editor das cartas da Madre Maria Joana, que é o mesmo autor que já escrevera a sua biografia e a editara em 1762 . Na "notícia ao leitor", confia o seguinte:

Satisfaremos ao teu desejo, a tua espiritualidade e à palavra que te deu o autor da vida da nossa Irmã Soror Maria Joana, religiosa professa do Coro neste Real Convento do Santíssimo Sacramento do Louriçal, falecida aos 25 de Março do ano de 1754. Se tens lido a sua vida, verias uma boa parte das suas cartas: agora as lerás inteiramente. Vão mudadas escassamente algumas palavras que convinha fiar do segredo [...)]. São copiadas das cartas originais que se guardam com precioso depósito no Arquivo do mesmo convento [...].

Verás nestas cartas eloquência do céu, e com uma mediana inteligência conhecerás a propriedade de termos tanto superiores à capacidade de uma mulher, quanto ela mesma duvidara da sua propriedade. Muito terás que aprender de penitência, de mortificação e de todas as virtudes, com esta lição, se o desejas; confio que o desejes com a lição e ainda creio mais, porque me persuado que antes de ler o desejas, porque te moves a abrir um livro de tal matéria, aonde só acharás interesses de tua alma, notícias e instrução para a piedade e salvação. [...] Estima este livro, que bem longe de encher-te de espécies perigosas, ele te instruirá e deleitará suavemente se o paladar de teu espírito não estiver

\footnotetext{
${ }^{23}$ Cf. I.POUTRIN, Le Voile et la plume, p. 25.

${ }^{24}$ Cf. M.V. MENDES, A oratória barroca de Vieira, p.304.
} 
inteiramente depravado. Entre as obras dos servos de Deus merecem as suas cartas especial estimação; e as de uma mulher como poucas, santa Teresa de Jesus, mereceram as ilustrações do Ilustríssimo Palafox. ${ }^{25}$

Uma obra, portanto, direcionada para o cristão em geral, representado neste "tu" com o qual se procura criar cumplicidade com o destinatário.

Já diferentemente atuou o Padre Simão Cardoso Pacheco, ao redigir a Vida e milagres da venerável Madre Soror Francisca da Conceição, religiosa no mosteiro de Santa Clara da Vila de Trancoso. No "Prólogo", confessa: "Para vós, e para vós somente, dignissimas e muito religiosas Senhoras, pretendo escrever a vida da Venerável Madre Soror Francisca da Conceição, irmã e contemporânea vossa”. Mas, como sabemos, uma vez saídas a lume, as obras eram lidas por todos, sendo essa afirmação um mero tópico de dedicação, reverência e estima.

Muitas biografias de religiosas (redigidas sobretudo no século XVIII) adquirem hoje um valor documental interessante, na medida em que nos permitem aceder não só à informação de que muitas religiosas escreviam, mas também a alguns fragmentos do que escreveram e que os seus biógrafos transcrevem. Aliás, alguns títulos de biografias anunciam, por vezes, que no discurso narrativo da vida de determinada religiosa se entrelaça o discurso da própria biografada, um discurso citado, dotado de uma certa autonomia em relação ao discurso do narrador-biógrafo e que individualiza ainda mais a personalidade da biografada. Assim, parece particularmente relevante o fato de já existir uma biografia de Soror Mariana da Purificação ${ }^{26}$., redigida em 1747 por Fr. Caetano do VENCIMENTO e intitulada Fragmentos da prodigiosa Vida da Venerável Madre Mariana da Purifcação, quando Fr. Miguel de Azevedo, cronista da Ordem, decide editar, em 1802, O Memorial das Instrutivas Palavras e Edificantes Obras da Muito Virtuosa Madre Mariana da Purificação, religiosa do Carmo Observante do Convento da Esperança de Beja. Frei Miguel de Azevedo anuncia justamente, logo desde o título ${ }^{27}$, que o leitor terá acesso às palavras da Madre Mariana. Essa biografia, de fato, merece registo, sobretudo por transcrever, entre outras modalidades discursivas, excertos das cartas que a religiosa escrevia a seu Confessor, a propósito dos anseios místicos em relação a Cristo, testemunhando uma prática de escrita por carta que se pode, por isso, supor bastante corrente no ambiente claustral português. O objetivo era criar modelos a imitar:

\footnotetext{
${ }^{25}$ Cf. Fr. J. de CAETANO, Memória da vida, sem páginas.

${ }^{26}$ Mariana da Purificação nasceu em Lisboa, a 5 de Novembro de 1623, filha de António de Azevedo e Maria da Cruz.

${ }^{27}$ Fr.M. de AZEVEDO, Memorial das Instrutivas Palavras, p.IV.
} 
Escrevi, pois, este Memorial [...] para o entregar a todos em comum, e muito particularmente a vós, seus piedosos afeiçoados, a fim de a imitardes quanto vos for possível. Vós não podeis ser amadores das virtudes em que floresceu a vossa Amada, não sendo delas imitadores. [...] Pelo que eu, neste Memorial que vos entrego, só refiro as palavras e obras da M.V.M. que vós, com o socorro divino, podereis imitar ${ }^{28}$.

Ao longo da narração da vida, o cronista transcreve, como se disse já, largos excertos das cartas que a carmelita dirigiu ao Confessor, como o que se transcreve de seguida, elucidativo da descrição e conta-corrente da vida espiritual da religiosa, que ela mesma minuciosamente anota:

Um dia de santa Maria Madalena de Pazzi, estando no Coro rezando matinas, me deu um incêndio de fogo tão forte, que me senti arder, e junto com um ímpeto de amor, que não cabia em mim; e aos efeitos que eu em mim sentia, não sei como não dei muitos gritos de amor; e se eu os dei ou não, me não acordo. Sempre tenho retratada no meu coração esta bendita Santa, e desejo muito imitá-la na superioridade com que amou a Deus sem cansar. É tal a força dos laços de amor a Deus, que só a obediência os pode soltar. Ainda quando durmo, o meu coração vigia. O coração do meu Esposo é para mim o meu Agulheiro, o meu centro, o meu almário, o meu retiro. Não sei que fazemos nós, Esposas de Cristo, que tanto nos divertimos de todo o nosso bem. Oh quem pudera apregoar por todo o Mundo este divino amor! Eu não sei que ama quem a Deus não ama. Eu não sei que quer quem a Deus não quer. Eu não sei que busca quem a Deus só não busca ${ }^{29}$. Eu não sei que vê quem a Deus só não vê com os olhos da fé. Oh grande cegueira do Mundo! Trabalhemos, Padre Confessor, trabalhemos nesta batalha, para que com o favor de Deus alcancemos o vencimento da perfeição de nossas vidas. ${ }^{30}$

A voz da religiosa é cedida pelo narrador aos leitores quase a cada página da biografia "Ardeu a caridade da M. R. M. M. num fogo volante, num fogo mineral, num fogo abrasador". Testemunha-o ela mesma:

Sucede-me muitas vezes que tais são os baques e saltos que me dá o coração no peito, que os ouço com os ouvidos corporais e desejo abrir o peito com

\footnotetext{
${ }^{28}$ Fr.M. de AZEVEDO, Memorial das Instrutivas Palavras, pp.: IV-V. O caráter tardio da impressão denota que ainda no século XIX as experiências místicas continuavam a interessar um público que se supõe alargado e influente. Esta redação tem lugar justamente depois da divulgação de que, em 1798, mais de um século volvido sobre a morte da religiosa, o seu corpo se apresentava incorrupto e flexível: "Renovou-se então nalguns fiéis e recresceu noutros a piedosa inclinação a esta grande Serva e muito amada Esposa de Jesus Cristo. Começaram todos a desejar e a pedir ansiosamente livros da sua pasmosa vida e preciosa morte".

${ }^{29}$ Note-se a influência dos textos de Santa Teresa sobre a espiritualidade e a escrita desta carmelita.

${ }^{30}$ Fr.M. de AZEVEDO, Memorial das Instrutivas Palavras, pp.71-72.
} 
as minhas próprias mãos, deixá-lo voar para onde ele quer e deseja tanto, mostrando que não quer viver em mim, senão no seu centro, que é o meu Divino Esposo. [...] Depois que estou neste retiro, os mais dos dias passo todos naquela união de meu Divino Esposo, toda unida e abrasada em seu divino e puro amor, sem me lembrar cousa desta vida, nem deste mundo, como se para mim o não houvera. ${ }^{31}$

Mais adiante, narra o biógrafo: "Acham-se espalhados pelos seus papéis os textos de Humildade, que transcrevo fielmente: 'Não tenho de mim o conhecimento que devo ter'; 'Sou a que sou, devendo ser a que não sou". ${ }^{32}$ Mas, de entre todos os textos escolhidos pelo biógrafo, talvez os que melhor permitem ver o sofrimento interior de quem se desejava perfeita na vida religiosa sejam aqueles em que refere as explosões de alegria por estar a rezar a quem amava, experimentando a vergonha de quebrar o silêncio da Regra ou a compostura de comportamento:

Dizem-me que hei de mister ser penitenciada; porque sou uma inquietadora, que inquieto as freiras em comunidade com as minhas festas; a que eu abaixo a cabeça e de boa vontade levara a penitência, se ma deram; e só sinto saberem ou alcançarem a causa por que me rio, que isso é o mais que me custa. [...] Dava às Noviças bem mau exemplo e algum motivo de escândalo a alguma que tivesse mais capacidade, porque estando com elas rezando as Horas de Nossa Senhora, me começava a rir sem me poder refrear nem sofrer. Por mais que queria dissimular o riso, não podia, e então elas me procuravam de que me ria e eu ficava envergonhada do mau exemplo que lhes dava. ${ }^{33}$

Merece registo, ainda, o curioso e significativo procedimento de Fr. Antônio de ALMADA. Ao publicar, em 1694, os Desposórios do espírito celebrados entre o divino amante e sua amada Esposa a Venerável Madre Soror Mariana do Rosário o religioso dá lugar a uma prática de escrita em que autoria feminina e masculina se mesclam e sobrepõem. Trata-se da autobiografia de uma religiosa que Antônio de Almada transforma em biografia, confessando ter tomado por base os "originais que ela escreveu por mandado do seu confessor" e que se conservavam no mosteiro. Da religiosa, falecida em 1649, mantém alguns excertos que entremeia na sua escrita: "Nas locuçôes, uso das mesmas formais palavras que o Senhor disse a sua serva”. Com essas afirmaçóesm aparenta respeitar uma parte da autoria do texto que toma da religiosa, mas não se deve esquecer também que, por este modo, se ilibava das responsabilidades de forjar afirmaçôes divinas ou de ter ficcionalizado

\footnotetext{
${ }^{31}$ Fr.M. de AZEVEDO, Memorial das Instrutivas Palavras, pp.74-75.

${ }^{32}$ Fr.M. de AZEVEDO, Memorial das Instrutivas Palavras, p.103.

${ }^{33}$ Fr.M. de AZEVEDO, Memorial das Instrutivas Palavras, pp.104-105.
} 
as experiências mais diretas da religiosa com Cristo. É, pois, em itálico que transcreve as falas resultantes do diálogo da religiosa com Cristo.

O amante celeste lhe falou e disse estas palavras: "Debaixo de uma árvore te ressuscitei e à sombra de outra te tenho em meus braços". Perguntou-lhe o Senhor amorosíssimo: "Filha, entendes isto que te digo?". Ao que ela, com a sua costumada humildade, respondeu: "Que há-de entender uma miserável pecadora?". Disse-lhe então o esposo soberano, explicando-lhe o mistério de suas palavras: "Filha, morrendo eu em uma cruz te ressuscitei e a sombra a que te pus foi a de meu corpo e sangue, com que recreio tua alma todas as vezes que comungas". ${ }^{34}$

Apenas mais um exemplo da manutenção do diálogo nesta narrativa, a propósito de um episódio sucedido por altura da comunhão.

"Filha, eis-me aqui, não tens mais que desejar". O Esposo a levou até ao sacrário de seu amoroso peito, e colocando-a junto à chaga de seu divino Lado, lhe mandou que pusesse nele a boca, e vendo-se tocar já daquele amoroso ósculo, lhe disse: "Farta a tua alma". ${ }^{35}$

Não é esse o único caso em que a escrita das religiosas aparece dirimida e transformada numa escrita masculina, que dela se apropria. A cronística conventual está repleta de exemplos de relatos que foram extraídos de narrativas biográficas de religiosas sobre companheiras suas que tinham como exemplo de maior virtude e santidade. Refira-se, a título de exemplo, a Relação do Convento das Religiosas Beneditinas da Cidade do Porto, manuscrito redigido por Soror Leonor de Magalhães (professa no Real Convento de Avé-Maria, falecida a 22 de dezembro de 1688, com mais de noventa anos), de que "se aproveitou o Licenciado Jorge Cardoso como confessa no $3^{\circ}$ Tomo do Agiol. Lusit., pag. 572 col. I e no Coment. De 6 de Junho letr. F"36.

De fato, Cardoso informa que o que relata dessa e de outras religiosas do Mosteiro de Ave-Maria do Porto "consta tudo de relaçôes desta casa, que nos vieram parar às mãos, feitas e apuradas com toda a verdade pela Madre Leonor de MagaIhães, e justificadas com certidão do P. Fr. Francisco da Trindade (que foi Prior de S. Bento de Lisboa) a 20 de Agosto de 1659". A justificação para essa apropriação

\footnotetext{
${ }^{34}$ Fr.M. de ALMADA, Fr.M. de ALMADA, Desposórios do espírito celebrados entre o divino amante e sua amada Esposa a Venerável Madre Soror Mariana do Rosário, p.96.

${ }^{35}$ Fr.M. de ALMADA, Fr.M. de ALMADA, Desposórios do espirito celebrados entre o divino amante e sua amada Esposa a Venerável Madre Soror Mariana do Rosário, p.101.

${ }^{36}$ Cf. D.B. MACHADO, Biblioteca Lusitana, p.12.
} 
que dissolve a escrita feminina parece-lhe simples: "E já que se extinguiram aqueles conventos, será bem que digamos brevemente o que deles alcançamos, para que de todo se não perca sua memória".

O mesmo aconteceu com as Relaçôes de algumas Religiosas do Convento de Chelas, redigidas por Soror Juliana de Jesus, religiosa do Convento de Chelas, de Cônegas Regrantes de Santo Agostinho, onde morreu com cem anos, a 18 de Maio de 1639: "como vemos das relaçôes que se nos comunicaram do convento de Chelas, escritas pela muito virtuosa Sor Juliana de Jesus, testemunha de maior exceição" 37 .

Para o contexto português, é de salientar que são muitas vezes os homens quem tira as religiosas do seu silêncio, obrigando-as a tomar voz que de outra forma não tomariam. A sua relação com o espaço que habitavam tornou-se, pois, muitas vezes, determinante da sua atividade literária. Enquanto escritoras sob esse preceito de obediência, e com a consciência de que os conteúdos que expunham pela escrita poderiam ter divulgação alargada, as religiosas atuavam em função de uma determinação superior e não em sintonia com a sua vontade própria ${ }^{38}$. Tal fato incutiu mais força e impacto ao que escreveram, quando se tratou de divulgar, por cópias várias, os escritos assim elaborados. No entanto, esse mesmo poder masculino foi que, muitas vezes, retirou voz às religiosas, fosse obrigando-as a queimar os seus escritos, fosse incorporando, às vezes sem nenhuma informação ou escrúpulo relativamente a essa apropriação, fragmentos textuais de religiosas em textos de autoria masculina.

Com essas ediçôes, os discursos ciciados ou silenciados extrapolam da sua inicial condição de privacidade e confidência para ganhar a dimensão pública que os tornaria modelares de uma forma de estar. Assim editados, contrariam a natureza da sua existência e as circunstâncias originais da sua circulação. Mas ajudam-nos a pensar a escrita feminina claustral como não a pensaríamos sem eles.

\section{III - Do espírito às letras}

De todo o exposto, parece poder concluir-se que, embora suscitada pelas companheiras, pela corte ou pelos superiores (ou brotando frequentemente de impulso próprio e desobrigado de qualquer cumprimento), a escrita monástica feminina não constituía norma consensual entre os mosteiros portugueses, pois de outro modo não teriam existido tantos escrúpulos, hesitações, dúvidas e polêmica em relação a ela. E de fato, para além de se constatar que a escrita (pelo menos a

\footnotetext{
${ }^{37}$ Cf. J.CARDOSO, Agiológio Lusitano dos Santos, p.63; D.B. MACHADO, Biblioteca Lusitana, p. 921.

${ }^{38}$ Variadas foram às vezes em que Soror Clara do Sacramento suplicou ao seu confessor autorização para queimar a autobiografia que escrevera ou que lhe pede autorização para não continuar (cf. A.M. de C.BRANCO, Autobiografia, p.12).
} 
literária ou a de caráter macroestruturalmente organizado) só tem inicialmente lugar junto das religiosas professas dos melhores conventos do país, cuja formação pré-conventual passara pelo acesso à cultura lida e escrita ${ }^{39}$, é claramente notória a dívida que a projeção dessa escrita feminina contraiu em relação à Santa Teresa, cuja edição das Obras Completas, mas, sobretudo das Cartas e do Libro de la Vida, permitiu a afirmação de uma referência incontornável neste terreno, pela associação entre literatura e espiritualidade. Por isso, Fr. José Caetano a refere no prólogo da edição que preparou das cartas de Soror Maria Joana, como acima se viu...

Quer no exterior quer no interior dos conventos, coexistem, em suma, duas atitudes de sinal contrário, relativamente ao exercício da escrita por parte das religiosas: o apreço e a desconfiança, a necessidade e a condenação.

Efetivamente, nem só por imposição ou contrariadas escreveram as religiosas portuguesas. Muitas faziam-no de moto próprio, levadas por inquietaçōes de natureza vária, ou por excesso e desbordamento de sentimento religioso. As cartas dirigidas a Fr. Antônio das Chagas pelas muitas religiosas com que este se correspondeu nada tinham de impositivo, na maioria dos casos.

As biografias que algumas escreveram para deixar memória de companheiras a quem reconheceram especial virtude e santidade resultaram, sobretudo da estima e veneração com que pretenderam glorificar a sua comunidade e a sua ordem. E a poesia, que tantas delas produziram na solidão das suas celas ou ermidas, de que não davam conhecimento a mais ninguém, existiu por necessidade do coração recluso e orante, ainda que possa também ter tomado raízes emprestadas à prática profana, que em moldes poéticos vertia a profusão de sentimentos, as contradiçôes da alma, os pensamentos mais recônditos.

Para além de poesia resultante de circunstancialismos vários e algumas vezes exteriores ao convento, uma poesia secreta, solitária, sem ouvintes nem testemunhas brotou de momentos de grande intensidade espiritual. A contemplação de imagens devotas ${ }^{40}$ ou a leitura de livros espirituais foi muitas vezes estímulo para expansōes

\footnotetext{
${ }^{39}$ De qualquer forma, é de assinalar que, nos registos dos questionários protocolares que tinham lugar após o noviciado e na véspera de se tornarem religiosas professas, grande parte das religiosas dos conventos de Lisboa escreve o seu nome, embora a análise da grafia possa revelar hábitos de maior ou menor prática de escrita. Não é possível esquecer, nesses pontos de situação, que muitos mosteiros tinham pupilas, que muitas senhoras foram educadas em conventos, mesmo não tendo depois seguido a vocação religiosa e que, por isso, os mosteiros exerceram, também, a sua função educativa não só na aprendizagem das primeiras letras, como no ensino do latim. Disso testemunha a Carta de Guia de Casados de D. Francisco Manuel de Melo, editada em Lisboa em 1651, quando registra o diálogo de uma senhora virtuosa e respeitável com o seu confessor, que estranhou ter ela começado por dizer a confissão em latim: "Padre, criei-me em mosteiro"(D.F.M. de MELO, Apólogos Dialogais, p.96). ${ }^{40} \mathrm{~A}$ poesia da religiosa Teresa Juliana de $\mathrm{S}$. Boaventura, editada justamente na sua biografia, esclarece-nos sobre muitos dos estímulos que terão estado por trás da produção monástica feminina. Veja-se o romance "A uma imagem de Cristo crucificado que lhe levaram à mostra, para exprimir o que dela sentia e dizia", que, longe de constituir uma poesia ecfrástica, expressa antes efeitos da contemplação da imagem sobre a vida interior da religiosa:
} 
místicas, que se registavam nas margens vazias dos livros. Assim se encontrou, por exemplo, um poema de Soror Violante de Jesus Maria, de que ninguém suspeitava a existência, suscitado pela leitura de Os trabalhos de Jesus, de Frei Tomé de Jesus. $\mathrm{E}$ a comunidade muitas vezes se rejubilava com esses textos que descobria ou com outros de que tinha conhecimento, apesar da reserva das autoras.

A Madre Soror Maria Madalena de Jesus, que produziu várias obras em modalidades diversas, que vão do registo poético ao escrito místico e ao texto litúrgico, escreveu, a acreditarmos em Fr. Jerônimo de Belém, um comentário parafrástico aos Salmos, intitulado Exposição Parafrástica de alguns Salmos de David em sentido mistico, dividida em duas partes, obra que as religiosas da comunidade muito valorizaram e que, "por ser feita em romance, se entrou na dúvida de poder-se usar dela sem escrúpulo; mas por se livrarem dele, recorreram as Religiosas ao Tribunal do Santo Ofício, donde alcançaram licença para o lerem, como a outro qualquer livro espiritual"11.

$\mathrm{O}$ apreço da comunidade foi, nesse caso, determinante para a sua escrita, em que a religiosa via uma forma de servir a Deus: "o mesmo conceito, que da sua virtude tinham as Freiras, era o motivo de lhe pedirem por escrito direcçôes para os dias da Comunhão, a que ela satisfazia pontualmente, pelo gosto, e desejo do espiritual aproveitamento de suas almas" 42 .

Os conventos, de fato, nem sempre olharam da mesma maneira a atividade literária das suas religiosas, que escreveram por motivos variados e com finalidades diversas. Pela escrita colocavam ordem nas suas emoções e organizavam interiormente as suas próprias experiências ${ }^{43}$. Pela escrita expressaram o inefável

\footnotetext{
"Quando me buscais, meu Bem,/Minha alma que vos dirá? /Dirá que vos quer seguir,/E convosco acabará" (Ver XAVIER 1752: 163-164). O poema aponta precisamente para a função das imagens nesse processo criativo. A obra Aves Ilustradas em avisos (...) de Soror Maria do Céu terá resultado também, provavelmente, da contemplação dos painéis azulejares existentes no claustro, com imagens várias de aves (cf I. MORUJÃO, Emblemas e Problemas em Aves Ilustradas em Avisos de Soror Maria do Céu. In: Emblemática y Religión en la Península Ibérica.).

${ }^{41} \mathrm{Fr} . J$. de BELÉM, Crônica Seráfica da Santa Provincia dos Algarves da Regular Observância do nosso Seráfico Padre S. Francisco, pp.367ss..

${ }^{42} \mathrm{Fr} . J$. de BELÉM, Crônica Seráfica da Santa Provincia dos Algarves da Regular Observância do nosso Seráfico Padre S. Francisco, pp.378-379.

${ }^{43}$ Ilustra essa situação a atitude de Soror Catarina do Salvador, referida pelo seu biógrafo: "O seu modo de meditar, e orar era o que deixou feito o padre Frei Estêvão da Purificação. E o do Padre frei Luís de Granada de suas meditações repartidas pela semana, e de outros livros espirituais"( ANÔNIMO, Breve Recopilação da vida e morte de Soror Catarina do Salvador Ms: fl. 40 v.). "E outros passos de muita devoção, que parece lhe serviam como de ensaio para quando havia de falar com Deus. E depois de falar saía dele com tal espírito, que punha em trovas às vezes os sentimentos que diante de Deus alcançava. E parece-me certo que depois dela ter tratado com Deus em oração, devia de fazer as que no seu breviário lhe acharam entre outras bem afeituosas, e devotas, que por ela nelas mostrar quanto fervor tinha na oração, as quero apontar aqui: É que tenho uma só alma me lembrar, /E que uma só vez hei-de morrer, / E tenho uma só vida que perder, / E uma glória só pera gozar. / Meu desejo será de a meu Deus ver / Meu temor de jamais nunca o largar./ De o não gozar será a minha dor, /
} 
e construíram memória coletiva ${ }^{44}$. Pela escrita responderam às necessidades espirituais de uma sociedade que procurava rumos para se orientar num mundo estranho, em mutação e quantas vezes contraditório em si mesmo ${ }^{45}$. Ora, se, para o caso da Soror Maria Madalena de Jesus, as religiosas manifestaram enorme aceitação - tal como o fizeram, também, com uma Soror Auta da Madre de Deus, também religiosa da Madre de Deus de Xabregas, que compôs o Ofício da Gloriosa Virgem e Mártir Santa Auta, editado em 1621, e que obteve autorização apostólica ${ }^{46}$ - outros foram os conventos e as religiosas que, por vezes, mesmo vivendo um clima cultural dinâmico, hostilizaram a atividade literária das suas companheiras, sobretudo quando a sua fama passava para fora dos limites do claustro:

Soror Maria de Jesus, religiosa do Convento de Santa Clara de Coimbra, entrou naquele convento com quatro anos de idade, para se criar na protecção de umas tias religiosas ${ }^{47}$, que a doutrinaram com desvelos de bem nascida; e logo dos primeiros anos o engenho a inclinou à lição dos Poetas. O estudo venceu a falta dos mestres com a doutrina dos livros, e conseguiu fazer-se douta na arte, discreta e fácil nas composiçóes métricas. Com o vento dos aplausos que lhe davam, caiu de desvanecida na vanglória de Poetisa, com grande descuido nas obrigações do estado, pelo interesse do estudo. Escreveu muitas poesias a vários assuntos; e ordenou algumas comédias que lhe deram merecidamente o nome de douta, o brasão de discreta. Pelos escritos a buscavam muitos fidalgos e homens doutos da Universidade, porque faziam gosto de a ouvirem pela discrição. Esta frequência de visitas parecia relaxação do estado às religiosas mais reformadas, e faziam às tias repetidas queixas; porém calavam a murmuração, gostosas de que a sobrinha tivesse tão bom-nome, adquirisse tão ilustre fama ${ }^{48}$.

\footnotetext{
Meu gozo o que me levar a meu Senhor (ANÔNIMO, Breve Recopilação da vida e morte de Soror Catarina do Salvador Ms: fl. 50 v. e 51).

${ }^{44}$ Citem-se as Memórias Históricas do Real Convento de Jesus de Setúbal, compostas por Soror Ana Maria do Amor Divino, religiosa do mesmo convento, para servirem de suplemento e continuação do Tratado da antiga e curiosa fundação [...], que compôs a Madre Sor Leonor de S. João, inseridas no Ms. 846 do A.N.T.T. (S.A.M. de AMOR DIVINO, Memórias Históricas do Real Convento de Jesus de Setúbal). De fato, muitas religiosas escreveram História, sendo as crônicas uma das modalidades discursivas que praticaram com frequência.

${ }^{45}$ Os paratextos das obras editadas (licenças, prólogos ao leitor, dedicatórias) são espaços particularmente expressivos dessa função.

${ }^{46}$ Cf. D.B. MACHADO, Biblioteca Lusitana, p. 440.

${ }^{47}$ Foi prática muito comum, nos sécs. XVII e XVIII, as sobrinhas de religiosas entrarem para os conventos para serem educadas na companhia de uma ou mais tias - sempre havia uma em algum mosteiro - e o grau de parentesco assegurava, quase sempre, a certeza de que, se optassem por seguir a vida religiosa, teriam vaga no mosteiro em causa. Lembremos, a título de exemplo, que Soror Helena da Cruz (1629-1721) tinha no Convento da Esperança uma tia professa.

${ }^{48}$ D.de F.PERIM, Teatro Heroino...,p.216.
} 
Ainda assim, são raros os relatos de hostilidades dessa natureza, talvez porque a poesia era bem acolhida no interior da clausura. Ou ainda porque a controlada imagem de vida religiosa que passava para o exterior deveria ser o mais depurada possível de sombras relativas à idealidade da vida comunitária.

Os comentários tecidos nas microbiografias que proliferam nas crônicas das ordens religiosas apresentam-se significativos da sensibilidade da época à prática literária das religiosas e ainda do sentimento de algumas destas face à sua própria produção.

Certas afirmações então feitas induzem-nos a pensar que a avaliação que as religiosas faziam da sua própria produção variava em função da fase da vida em que se encontravam. Soror Maria da Circuncisão, "por alturas da morte", procurou destruir as suas obras, "ainda sendo muitas ao divino", "julgando por ociosidade o que em outro tempo fora lícita ocupação do discurso". Assim, mais perto da morte, quando o despojamento interior que permite o franqueamento total à vida em Cristo tudo avaliava, aquilo que antes fizera parte de uma forma de estar aceite na comunidade conventual e social revela-se destituído de sentido. Quando a contrição pesa cada gesto passado, avaliando-o em função da comunhão que estabeleceu com Cristo, a apreciação dos atos de inscrição mais coletiva e social é feita em termos de "ociosidade" e procuram queimar o que escreveram. Mas o fogo, mesmo destruindo os textos, não apagou a necessidade ou a motivação que lhes deu origem.

O fogo purificador redimiria talvez, na provável opinião das religiosas, os versos sempre inferiores ao ideal de perfeição de vida religiosa e de relação com Deus. Por isso, algumas religiosas queimavam elas próprias as suas produções (como fez, por exemplo, Soror Isabel Auta de S. José, 49 "que só do fogo fiava os seus escritos" ${ }^{50}$ ); e outras, surpreendidas por doença súbita ou pela proximidade da morte, solicitavam às suas companheiras o favor dessa destruição, favor nem sempre cumprido, quantas vezes por pressão da população exterior à clausura, que, a partir de meados do séc. XVII, criou uma verdadeira órbita de curiosidade em torno dos conventos femininos ${ }^{51}$,

\footnotetext{
${ }^{49}$ Religiosa do convento da Madre de Deus de Xabregas, para onde entrou a 30 de Novembro de 1689 e onde morreu em 1752, com 85 anos.

${ }^{50} \mathrm{O}$ fogo foi também o destino que deu a muitas obras suas Soror Maria Madalena de Jesus, que sempre procurava "reduzir a cinzas" a sua obra, "porque a sua humildade lhe negava o valor e a estimação devida à preciosidade de seus escritos” (cf. Fr.J. de BELÉM, Crônica Seráfica ..., pp.406-408).

${ }^{51}$ Apenas para consolidar essa ideia de circulação alargada de textos, refira-se a informação dada por BELÉM (Fr.J. de BELÉM, Crônica Seráfica ..., p.367) em que, a propósito de um romance de Soror Maria Madalena de Jesus, "fundado no $1^{\circ}$ verso do Salmo Quemadmodum desiderat cervus ad fontes aquarum, ita desiderat anima mea ad te Deus", se diz que este romance "se conservou em vida da serva de Deus no seu próprio original, mas por sua morte desapareceu; ou porque ela o haveria queimado, ou porque a piedade devota o alienou da clausura". (Fr.J. de BELÉM, Crônica Seráfica ..., p.533).
} 
espicaçando-os à escrita, solicitando máximas ${ }^{52}$, conselhos, normas e modelos. Daí nascerá uma vasta produção impressa, cujos textos preliminares denunciam uma relação de expectativa e retorno entre a corte e os conventos.

De todo o modo, a inquietação experimentada tantas vezes por algumas religiosas face à sua atividade poética parece sintomática de uma ainda hesitante condição de escrita, quer feminina, quer conventual, ou, talvez melhor, de uma ainda não esclarecida posição face a eventuais conflitos entre a vida consagrada a Deus e a prática de escrita ${ }^{53}$. De outro modo, por que se inquietariam as religiosas de versos seus saídos de momentos em que o amor a Deus extravasava ${ }^{54}$ do coração em molde poético ou em cuidada prosa?

Sinais de fogo interior das almas devotas e apaixonadas pelo seu Senhor ${ }^{55}$, ou condenados ao fogo purificador por quem d'Ele se procurou aproximar, os textos emergentes da clausura feminina portuguesa constituem uma realidade incontornável, ainda que hoje dificilmente apreensível em toda a sua dinâmica e extensão. Por isso, será talvez no gesto de escrever, mais do que no resultado dele, que deveremos procurar o traço determinante de toda a produção literária feminina conventual, que nos permitirá aproximar-nos desse momento irreconstituível do impulso da escrita, como marca de identidade da vivência espiritual no espaço monástico feminino da Idade Moderna.

\section{BIBLIOGRAFIA}

AMOR DIVINO, Soror Ana Maria do Memórias Históricas do Real Convento de Jesus de Setúbal, compostas por Soror Ana Maria do Amor Divino, Ms. 846 do Arquivo Nacional da Torre do Tombo, sem ano.

ANÔNIMO, Breve Recopilação da vida e morte de Soror Catarina do Salvador, Religiosa do Mosteiro da Esperança de Vila Viçosa, Ms. 517, fl. 50v e 51 da Biblioteca da Academia das Ciências de Lisboa, sem ano.

\footnotetext{
${ }^{52}$ Soror Maria do Céu produziu umas Verdades do Tempo e umas Máximas do Século para a Marquesa de Marialva, textos esses que permaneceram manuscritos e esquecidos até ao século XX. Sobre estes dois textos, cf, I. MORUJĀO, Verdades do Tempo e Máximas do Século: dois manuscritos inéditos de Soror Maria do Céu. In: Revista da Faculdade de Letras - Linguas e Literaturas.

${ }^{53}$ Releia-se, como sinal dessa não afinada sensibilidade relativamente à escrita conventual feminina, as palavras de D. Francisco Manuel de Melo, no Apólogo Dialogal Hospital das Letras, onde, pela boca do Autor se afirma o seguinte: "Soror Violante do Céu foi a compositora dessoutro livrinho feito público por D. Leonardo; ambas as cousas a meu juízo escusadas por decoro de duas pessoas religiosas interpostas nesta discreta ociosidade" (D.F.M. de MELO, Apólogos Dialogais , p.186).

${ }^{54}$ A descrição dessas obras poéticas saídas da clausura feminina apresenta-as frequentemente como versos "cheios do fogo do amor de Deus, que ardia na fornalha da [...] alma" ou "excessos de amor" (J.CARDOSO, Agiológio Lusitano dos Santos, pp. 345 e 646, respectivamente).

${ }^{55}$ Foi justamente nesta perspectiva de expressão de fogo interior que a época, embora lata, entendeu muitos dos escritos das religiosas portuguesas.
} 
ANÔNIMO, Vida e Obras da Serva de Deus a Madre Mariana Josefa Joaquina de Jesus, religiosa carmelita descalça do Convento de Santa Teresa do lugar de Carnide. Lisboa: Régia Oficina Tipográfica, 1783

AA. VV. Per lettera. La scrittura epistolare femminile tra archivio e tipografia, secoli XV-XVII. A cura di Gabrilla Zarri. Roma: Viella, 1999.

ALBERIGO, G. (org.). LES Conciles Ecuméniques 2, Les Décrets. De Trente à Vatican II. Paris: Cerf, 1994.

ALMADA, Fr. Miguel de, Desposórios do espirito celebrados entre o divino amante e sua amada Esposa a Venerável Madre Soror Mariana do Rosário, religiosa de véu branco no convento do Salvador da cidade de Évora. Lisboa: Manuel Lopes Ferreira, 1694.

ANDRADA, Diogo Paiva de. Casamento Perfeito. Lisboa: Jorge Rodrigues, 1630.

AZEVEDO, Fr. Miguel de. Memorial das Instrutivas Palavras e Edificantes Obras da Muito Virtuosa Madre Mariana da Purificação. Lisboa: Oficina de Simão Tadeu Ferreira, 1802. BELÉM, Fr. Jerônimo de. Crônica Seráfica da Santa Província dos Algarves da Regular Observância do nosso Seráfico Padre S. Francisco. Em que se trata de sua Origem, Progressos e Fundaçôes de seus conventos. Lisboa: Oficina de Inácio Rodrigues, 1750-1758.

BÉRIOU, Nicole. L'Avènement des maîtres de la Parole. La prédication à Paris au XIIIe siècle, vol. I. Paris: Institut d'Études Augustiniennes, 1998.

BRANCO, Antônia Margarida de Castelo. Autobiografia (1652-1714), Prefácio e transcrição de João Palma-Ferreira. Lisboa: Imprensa Nacional-Casa da Moeda, 1983.

CAETANO, Fr. José. Memória da vida, e virtudes da serva de Deus Soror Maria Joana, religiosa do Convento Real do Santíssimo Sacramento do Louriçal. Lisboa: Miguel Rodrigues, 1762.

CARDOSO, Jorge. Agiológio Lusitano dos Santos, e varões ilustres em virtude do Reino de Portugal, e suas conquistas. Consagrado aos Gloriosos S. Vicente, e S. Antônio, insignes Patronos desta ínclita cidade de Lisboa, Tomo III. Lisboa: Oficina Craesbeekiana, 1652. (Edição facsimilada de FERNANDES, Maria de Lurdes Correia 2002, Porto, Faculdade de Letras da Universidade do Porto).

CASTIGLIONE, Baltasar. Il Cortegiano, Veneza 1528.

CÉU, Soror Maria do. Aves Ilustradas em Avisos para as Religiosas servirem os oficios nos seus Mosteiros. Lisboa: Oficina de Miguel Rodrigues, 1734.

CHAGAS, Fr. Antônio das . Cartas Espirituais (Reedição, notas e apresentação de Isabel Morujão). Porto: Campo das Letras, 2000.

FRANCO, José Eduardo; MORÁN CABANAS, Maria Isabel. O Padre Antônio Vieira $e$ as Mulheres. O mito barroco do universo feminino. Porto: Campo das Letras, 2008.

HEIDEGGER, M. L'Être et le Temps. Paris : Gallimard, 1964 [1927].

HEIDEGGER, M., L'art et l'espace. In : Questions IV. Paris : Gallimard, 1976 [1969].

LES CONCILES Ecuméniques 2, Les Décrets. De Trente à Vatican II (sous la direction de G. Alberigo). Paris : Cerf, 1994.

MACHADO, Diogo Barbosa. Biblioteca Lusitana, tomo III. Coimbra: Atlântida Editora, 1965-1967.

MELO, D. Francisco Manuel de. Carta de Guia de Casados, Edição de Maria de Lurdes Correia Fernandes. Porto: Campo das Letras, 2003. 
MELO, D. Francisco Manuel de. Apólogos Dialogais, vol. II - Escritório Avarento e Hospital das Letras, Prefácio e Notas do Prof. José Pereira Tavares. Lisboa: Sá da Costa, 1959.

MENDES, Margarida Vieira. A oratória barroca de Vieira. Lisboa: Ed. Caminho, 1989.

MORUJÃO, Isabel, Emblemas e Problemas em Aves Ilustradas em Avisos de Soror Maria do Céu. In: Emblemática y Religión en la Península Ibérica (Siglo de Oro), eds. Ignacio Arellano y Ana Martínez Pereira. Pamplona: Universidad de Navarra, 2010, pp. 283-301.

MORUJÃO, Isabel, Verdades do Tempo e Máximas do Século: dois manuscritos inéditos de Soror Maria do Céu. In: Revista da Faculdade de Letras - Linguas e Literaturas, Porto, II Série, vol. IX, 1992, pp.299-307.

PERIM, Damião de Froes Teatro Heroino, Abcedário Histórico, e Catálogo das Mulheres Ilustres em Ciências e Artes Liberais, Tomo I. Lisboa: Régia Oficina Silviana e da Academia Real, 1740.

POUTRIN, Isabelle. Le Voile et la plume. Autobiographie et sainteté féminine dans l'Espagne moderne. Madrid : Casa de Vélásquez, 1995.

RIBEIRO, Bernardim. História de Menina e Moça, Reprodução Facsimilada da Edição de Ferrara, 1554. Lisboa: Fundação Calouste Gulbenkian, 2002.

SANTA MARIA, Soror Tomásia Caetana de Expressões de um devoto arrependimento à imagem de Cristo Crucificado, que se venera no Convento de Santa Cruz de Vila Viçosa. Lisboa: Oficina Alvarense, 1743.

SOUSA, Bernardo Vasconcelos. Ordens religiosas em Portugal. Das origens a Trento - Guia Histórico. Lisboa: Livros Horizonte, 2005.

TAYLOR, Jane H. M.; SMITH, Lesley. Women and the book. Assessing the visual evidence, edited by Jane H. M. Taylor and Lesley Smith. London: The British Library and University of Toronto Press,

1996.

VENCIMENTO, Fr. Caetano do. Fragmentos da prodigiosa Vida da Venerável Madre Mariana da Purificação. Lisboa: Oficina de Antônio da Silva, 1747.

VELHO, Manuel (Pseudônimo Fr. Manuel Guilherme O.P.) Cartas Directivas e Doutrinais. Respostas de uma religiosa capucha e reformada a outra freira que mostrava querer reformar-se. Lisboa Ocidental: Oficina de Antônio Pedroso Galrão, 1730.

VIEIRA, Padre Antônio, Sermões. Reprodução facsimilada da edição de 1696, S. Paulo, Ed. Anchieta S.A. 1945.

XAVIER, Francisco. Clamores do Céu aos coraçôes da terra. Relação abreviada da exemplar vida e obras da Venerável Esposa de Jesus Cristo, a muito reverenda Madre Sor Teresa Juliana de S. Boaventura, religiosa do muito nobre Mosteiro de Santa Clara desta cidade de Lisboa, $2^{\text {a }}$ parte (Obras). Lisboa: Oficina de Francisco da Silva, 1752. 